Research Article

\title{
Comparison of hydrolysis and oxidation reactions of carbonyl sulfide on particle matter
}

\author{
Hailin Wang, Jie Cheng, Jinjun Li and Zhengping Hao* \\ Research Center for Eco-Environmental Sciences, Chinese Academy of Sciences, Beijing, 100085, P. R. China
}

Received 12 June 2007; Accepted 9 April 2008

\begin{abstract}
Reactions of carbonyl sulfide (OCS) on atmospheric particles were investigated in a flowing system using Fourier transform infrared (FTIR) at $293 \mathrm{~K}$. Results show that OCS could be slowly oxidized and hydrolyzed on atmospheric particles. As a simplified model, alumina $\left(\mathrm{Al}_{2} \mathrm{O}_{3}\right)$ was used to further compare the two reactions and the results indicate that hydrolysis reaction of OCS has an advantage over oxidation reaction to take place at a given time and that heterogeneous reactions of OCS on particles at atmospheric conditions may include oxidation and hydrolysis reactions. To explore the effect of metals on hydrolysis reaction, zinc $(\mathrm{Zn})$, iron $(\mathrm{Fe})$, calcium $(\mathrm{Ca})$, and magnesium $(\mathrm{Mg})$ supported on $\mathrm{Al}_{2} \mathrm{O}_{3}$ were prepared by incipient wetness method, and the results suggest that all metal oxides significantly enhance the initial intrinsic activity of OCS when compared with unmodified $\mathrm{Al}_{2} \mathrm{O}_{3}$. The $\mathrm{Zn}$-modified $\mathrm{Al}_{2} \mathrm{O}_{3}$ gives a significant increase of $\mathrm{CO}_{2}$ produced throughout the time-scale of these experiments and the possible reaction processes are proposed. (c) 2008 Curtin University of Technology and John Wiley \& Sons, Ltd.
\end{abstract}

KEYWORDS: carbonyl sulfide; alumina; oxidation; hydrolysis; FTIR

\section{INTRODUCTION}

Carbonyl sulfide (OCS) is one of the most important trace gases in the atmosphere. Its high abundance and long lifetime make it an important source gas of the global stratospheric aerosol sulfate. ${ }^{[1]}$ Heterogeneous interactions of these gases with atmospheric particles could directly influence the atmospheric quality. ${ }^{[2]}$ When referred to OCS, most researchers focus on the homogeneous reaction of OCS with free radicals in the gas phase and the consumption of OCS by plants, soil, and so on. ${ }^{[3]}$ Studies about the heterogeneous reaction of OCS on the surface of atmospheric particles are less, though some researchers investigated the oxidation of OCS on atmospheric particles. ${ }^{[4,5]}$ Chen et al. studied heterogeneous reactions of OCS over hematite and its mixtures, and a more detailed reaction mechanism was proposed. ${ }^{[6]}$ While, in industry, researchers focus on OCS removal by hydrolysis reaction ${ }^{[7-9]}$ knowledge about the hydrolysis reaction of OCS on atmospheric particles is still lacking. Since atmospheric particles are complex, besides the oxidation of OCS mentioned above, the hydrolysis reaction of OCS on atmospheric particles may also take place. Thus, the purpose of this article is to investigate the oxidation and hydrolysis

*Correspondence to: Zhengping Hao, Research Center for EcoEnvironmental Sciences, Chinese Academy of Sciences, Beijing, 100085, P. R. China. E-mail: zpinghao@rcees.ac.cn reactions of OCS on atmospheric particles under ambient temperature. Additionally, $\mathrm{Al}_{2} \mathrm{O}_{3}$ and $\mathrm{Al}_{2} \mathrm{O}_{3}$ with supported metals are used to give a further assessment of the two reactions.

\section{EXPERIMENTAL SECTION}

\section{Materials}

Atmospheric particles were collected at RCEES (Research Center for Eco-Environmental Sciences) during the sandstorm period in Beijing between 17th and 20th March 2006. That could be the representation of typical atmospheric particles in that they had a longrange transport over scales of thousands of kilometers from their sources, which made it possible to mix with other particles or interact with pollutants along the way. $\mathrm{Al}_{2} \mathrm{O}_{3}$ (Shandong Aluminum Inc.) was baked at $573 \mathrm{~K}$ for $4 \mathrm{~h}$ to eliminate the possible impurities adsorbed on the sample surface. $\mathrm{Al}_{2} \mathrm{O}_{3}$-supported metal oxide samples, including the oxides of zinc, iron, calcium and magnesium, were prepared by incipient wetness impregnation method using solutions of the metal nitrates as metal precursors and the impregnated samples were calcined at $773 \mathrm{~K}$ for $5 \mathrm{~h}$. The specifications of gases used here are as follows without further purification: OCS (2000 ppm, OCS/ $\mathrm{N}_{2}$, Beijing Huayuan Gases Inc.), Air 
(Beijing AP Beifen Gases Inc.), $\mathrm{N}_{2}$ (99.9\% purity, Beijing AP Beifen Gases Inc.).

\section{Analytical measurements}

\section{Element analysis}

Atmospheric particle samples were digested at $443 \mathrm{~K}$ for $4 \mathrm{~h}$ in a high-pressure Teflon digestion vessel with $3 \mathrm{ml}$ concentrated $\mathrm{HNO}_{3}, 1 \mathrm{ml}$ concentrated $\mathrm{HClO}_{4}$, and $1 \mathrm{ml}$ concentrated HF. After cooling, the solutions were dried, diluted to $10 \mathrm{ml}$ with $10 \% \mathrm{HNO}_{3}$, and then the main elements were determined by inductively coupled plasma-optical emission spectrometer (ICPOES) (PerkinElmer Inc.).

\section{Brunauer-Emmett-Teller experiment}

The nitrogen adsorption-desorption isotherms were obtained at $77 \mathrm{~K}$ over the whole range of relative pressures, using a NOVA 1000 (Quantachrome Inc.). Specific areas were computed from these isotherms by applying the Brunauer-Emmett-Teller (BET) method.

\section{FT-IR experiment}

A self-made laboratory microreactor using a quartz U-tube reactor was employed to investigate the reactions. For oxidation reaction, OCS was diluted with air (treated with soda-lime to remove the possible water and carbon dioxide) to $500 \mathrm{ppm}$ and then allowed to flow through particle samples, while for the hydrolysis reaction, $\mathrm{N}_{2}$ was introduced through a water saturator system to dilute the OCS to the same level. The flow rate was controlled by using calibrated mass flow controllers and the overall gas hourly space velocity (GHSV) of the reaction mixture was controlled at $1000 \mathrm{~h}^{-1}$. The

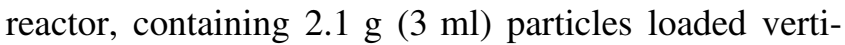
cally and tightly to avoid any vortex, was immersed in a water bath under thermostatic control at $293 \mathrm{~K}$. Final gaseous reactants and products were analyzed by a Fourier transform infrared (FTIR) (Tensor 27, Bruker Inc.) at ambient pressure (see Figs 1-2). Spectra were collected and the concentrations of gaseous products were calculated by using OPUS4.2 software.

\section{RESULTS AND DISCUSSION}

Owing to instrument limit, no other gas was detected except $\mathrm{CO}_{2}$ and OCS. Since there was no $\mathrm{CO}_{2}$ at first, tests were also done by sealing certain $\mathrm{OCS}$ and $\mathrm{CO}_{2}$ in the experimental system for several hours to investigate gas fluctuation induced by the experimental system, and the results showed that the whole experimental system was steady. We found that during the reaction process, $\mathrm{CO}_{2}$ was observed as OCS was consumed. Here, the

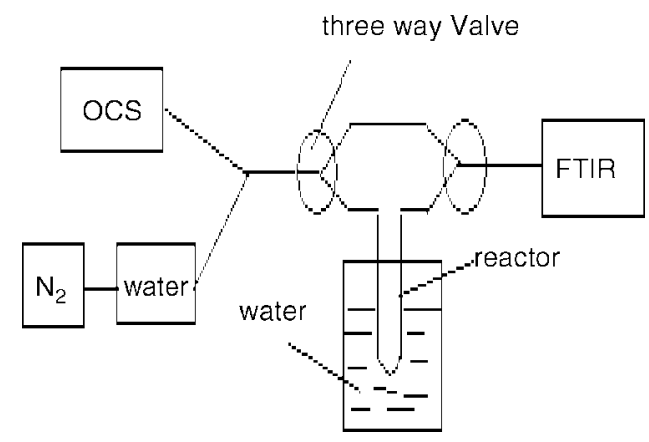

Figure 1. Sketch for hydrolysis reaction device.

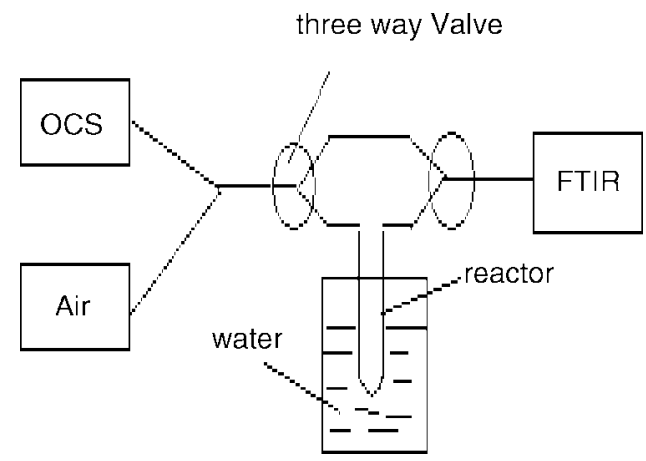

Figure 2. Sketch for oxidation reaction device.

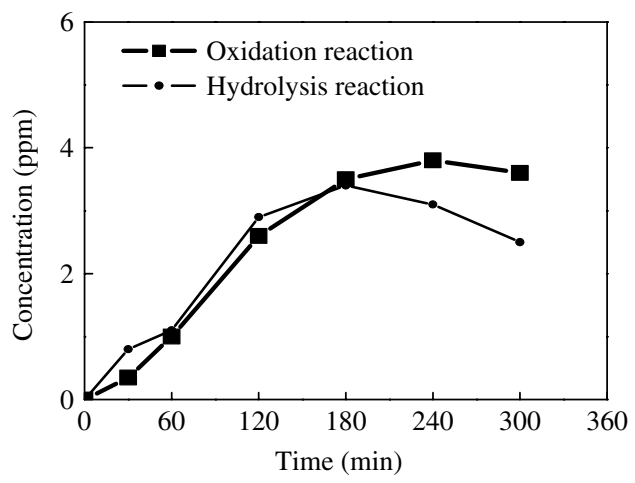

Figure 3. Changes of $\mathrm{CO}_{2}$ over atmospheric particles at $293 \mathrm{~K}$.

formation of $\mathrm{CO}_{2}$ could be used to judge the priority of the two reactions.

Figure 3 gave the results of the oxidation and hydrolysis reactions of OCS on atmospheric particles. Both curves showed very slow increase of $\mathrm{CO}_{2}$ in $5 \mathrm{~h}$, suggesting the atmospheric particles used here were relatively inert for the heterogeneous reactions of OCS. As particles were collected during the sand storm period, they might have mixed with other particles or interacted with pollutants during the long distance of transport as mentioned above. However, a small difference could 
be observed, in the first hour, as the amount of $\mathrm{CO}_{2}$ produced by hydrolysis reaction was a little more than that by oxidation, and at $180 \mathrm{~min}$, it reached the peak, while for the oxidation reaction, maximum $\mathrm{CO}_{2}$ amount appeared at $240 \mathrm{~min}$, later than the hydrolysis reaction. When comparing the OCS consumption in the two reactions, both reached balance in 30 min with consumption of not more than $10 \mathrm{ppm}$. The variances between the changes of $\mathrm{CO}_{2}$ and OCS in both reactions could be simply explained as follows: firstly, OCS was adsorbed on atmospheric particles, which was a physical adsorption and quickly reached a balance, and the following reactions belonged to the chemical changes, which were rather complex than the physical adsorption.

Generally, the total amount of $\mathrm{CO}_{2}$ produced by the hydrolysis reaction is about a little more than that by oxidation, but both of them do not give an obvious difference. Since $\mathrm{Al}_{2} \mathrm{O}_{3}$ is one of the main components of atmospheric particles, with large surface area and high catalytic activity, as a simplified model, $\mathrm{Al}_{2} \mathrm{O}_{3}$ was used to further investigate these two reactions, and the results are shown in Figs 4-5.

Comparing Fig. 4 with Fig. 3, we noted that the increased $\mathrm{CO}_{2}$ produced by OCS oxidation on $\mathrm{Al}_{2} \mathrm{O}_{3}$ had the same trend, but was more notable than that on the atmospheric particulates, and at $240 \mathrm{~min}$ it reached the peak of $6.9 \mathrm{ppm}$, which was about two times the value observed on the atmospheric particles. The hydrolysis reaction of OCS on $\mathrm{Al}_{2} \mathrm{O}_{3}$ was quite different from the hydrolysis reaction on the atmospheric particles, as at $30 \mathrm{~min}, \mathrm{CO}_{2}$ reached the peak of $5.1 \mathrm{ppm}$, then decreased quickly, and after 180 min no $\mathrm{CO}_{2}$ was observed. The obvious difference between the hydrolysis reactions of OCS on $\mathrm{Al}_{2} \mathrm{O}_{3}$ and the atmospheric particles could be related to the fact that $\mathrm{Al}_{2} \mathrm{O}_{3}$ was a

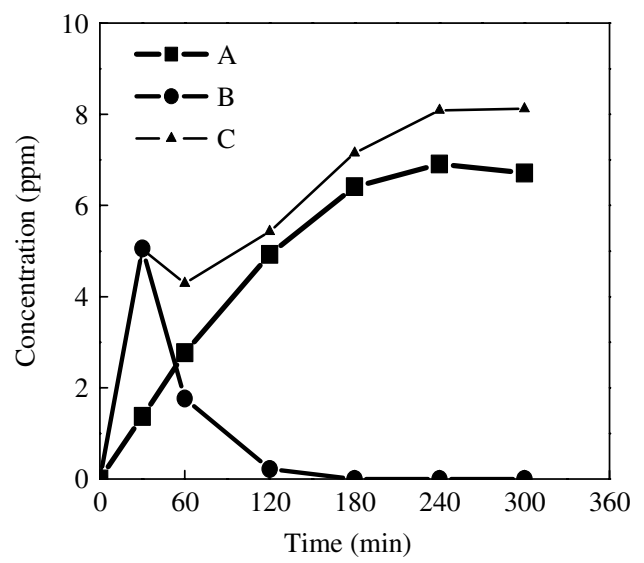

Figure 4. Changes of $\mathrm{CO}_{2}$ over $\mathrm{Al}_{2} \mathrm{O}_{3}$ at 293 K. (A) Oxidation reaction (B) Hydrolysis reaction $(C)$ Reaction including both air and water conditions.

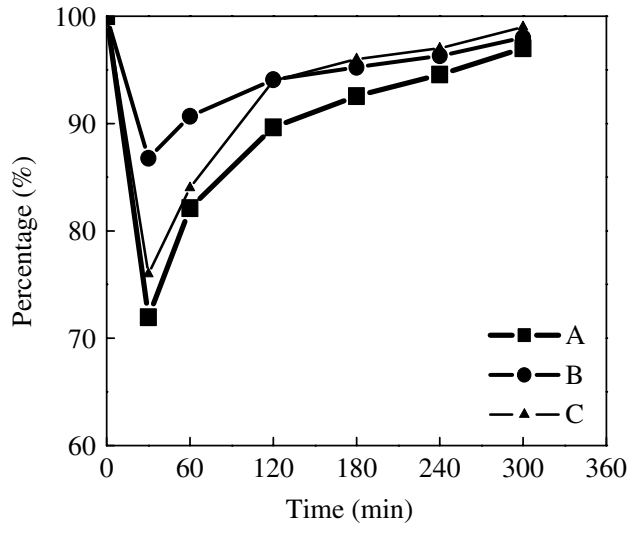

Figure 5. Balance of OCS over $\mathrm{Al}_{2} \mathrm{O}_{3}$ at 293 K. (A) Oxidation reaction (B) Hydrolysis reaction $(C)$ Reaction including both air and water conditions.

simple compound, and the atmospheric particle compositions were rather complex so that some other components might also work during the hydrolysis process. In Fig. 5, more OCS was consumed on $\mathrm{Al}_{2} \mathrm{O}_{3}$ than that on the atmospheric particles. For the hydrolysis reaction, the percent of OCS at 30 min was the least during the whole reaction time, $72 \%$, smaller than that for the oxidation reaction at the same time. After $30 \mathrm{~min}$, the trend began to go up and after $180 \mathrm{~min}$, no change of OCS was observed. Comparing both reactions of OCS on $\mathrm{Al}_{2} \mathrm{O}_{3}$, we found that the hydrolysis reaction was a quicker reaction; the reaction rate reached the top in a short time, then slowed down, and after a long time it reached the balance. The oxidation reaction was a relatively slow reaction process, and $\mathrm{CO}_{2}$ increased rather slowly as a function of time. However, compared with both reactions on atmospheric particles, we found the two reactions of OCS on $\mathrm{Al}_{2} \mathrm{O}_{3}$ were more evident, and it might be related with the particle surface area (Table 1), as atmospheric particle had a surface area of $4.11 \mathrm{~m}^{2} / \mathrm{g}$, and the surface area of $\mathrm{Al}_{2} \mathrm{O}_{3}$ was $133 \mathrm{~m}^{2} / \mathrm{g}$. Larger surface area meant more OCS molecules could be adsorbed. Besides the surface area factor, the free radicals $(\mathrm{OH})$ on the surface of $\mathrm{Al}_{2} \mathrm{O}_{3}$ might play an important role in the heterogeneous reactions of OCS. As a result, more $\mathrm{CO}_{2}$ was produced and more OCS was consumed on $\mathrm{Al}_{2} \mathrm{O}_{3}$ than on the atmospheric particles. When comparing the two reactions on $\mathrm{Al}_{2} \mathrm{O}_{3}$, the hydrolysis reaction had an advantage over the oxidation reaction due to more $\mathrm{CO}_{2}$ formed and more OCS consumed in a short time. To confirm our assumption, the following experiment was done: OCS was diluted to $500 \mathrm{ppm}$ with air that flowed through a water saturator system, and then passed through $\mathrm{Al}_{2} \mathrm{O}_{3}$. The results were also shown in Figs 4-5 (curve $\mathrm{C}$ ). In the first hour, curve $\mathrm{C}$ (Fig. 4) had the same reaction trend as the hydrolysis reaction (curve B), and after an hour, it 
was more similar to the processes of the oxidation reaction. In Fig. 5, in the first hour, curve $\mathrm{C}$ was close to curve $\mathrm{B}$, and after an hour, curve $\mathrm{C}$ was more close to curve A (oxidation reaction). So, we supposed that hydrolysis reaction of OCS on the atmospheric particulates was more preponderant, and when the hydrolysis reaction was over, the advantage of oxidation could be displayed based on $\mathrm{Al}_{2} \mathrm{O}_{3}$ model.

From the above, we see that the hydrolysis of OCS is a quick reaction and more like a catalysis reaction in which metals might play an important role. In fact, atmospheric particles include abundant metals, and the main elemental concentrations are given in Table 2. In order to explore the effect of these metals on the hydrolysis of OCS, $\mathrm{Fe}, \mathrm{Ca}, \mathrm{Mg}$, and $\mathrm{Zn}$ were selected and $\mathrm{Al}_{2} \mathrm{O}_{3}$ was modified by the addition of the above metals using the incipient wetness method. The results are shown in Figs 6-7.

Table 1. Specific areas of the atmospheric particles, $\mathrm{Al}_{2} \mathrm{O}_{3}$, and the modified $\mathrm{Al}_{2} \mathrm{O}_{3}$ samples.

\begin{tabular}{lcc}
\hline Sample & $\begin{array}{c}\text { Modifier } \\
\text { concentration }(\%)\end{array}$ & $\begin{array}{c}\text { Surface area } \\
\left(\mathrm{m}^{2} / \mathrm{g}\right)\end{array}$ \\
\hline Atmospheric particle & - & 4.1 \\
$\mathrm{Al}_{2} \mathrm{O}_{3}$ & - & 133 \\
$\mathrm{ZnO} / \mathrm{Al}_{2} \mathrm{O}_{3}$ & 3 & 122 \\
$\mathrm{Fe}_{2} \mathrm{O}_{3} \mathrm{Al}_{2} \mathrm{O}_{3}$ & 3 & 128 \\
$\mathrm{CaO} / \mathrm{Al}_{2} \mathrm{O}_{3}$ & 3 & 116 \\
$\mathrm{MgO} / \mathrm{Al}_{2} \mathrm{O}_{3}$ & 3 & 107 \\
\hline
\end{tabular}

Table 2. Main elemental composition of atmospheric particles(calculated as oxide).

\begin{tabular}{lcccccc}
\hline Elements & $\mathrm{Al}$ & $\mathrm{Ca}$ & $\mathrm{Fe}$ & $\mathrm{Mg}$ & $\mathrm{Ti}$ & $\mathrm{Zn}$ \\
\hline Percentage & 12.8 & 9.4 & 7.2 & 2.1 & 0.8 & 0.5
\end{tabular}

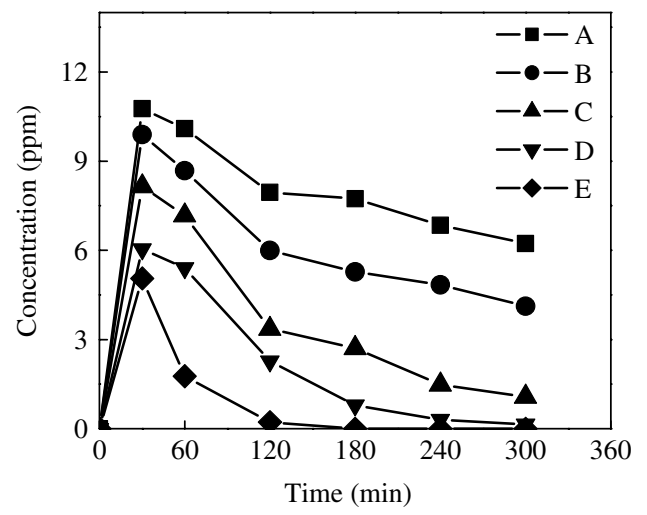

Figure 6. Changes of $\mathrm{CO}_{2}$ over different particles at $293 \mathrm{~K}$ during the hydrolysis

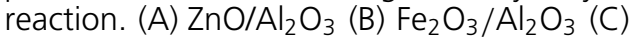
$\mathrm{Fe}_{2} \mathrm{O}_{3} \mathrm{Al}_{2} \mathrm{O}_{3}$ (D) $\mathrm{CaO} / \mathrm{Al}_{2} \mathrm{O}_{3}$ (E) $\mathrm{Al}_{2} \mathrm{O}_{3}$.

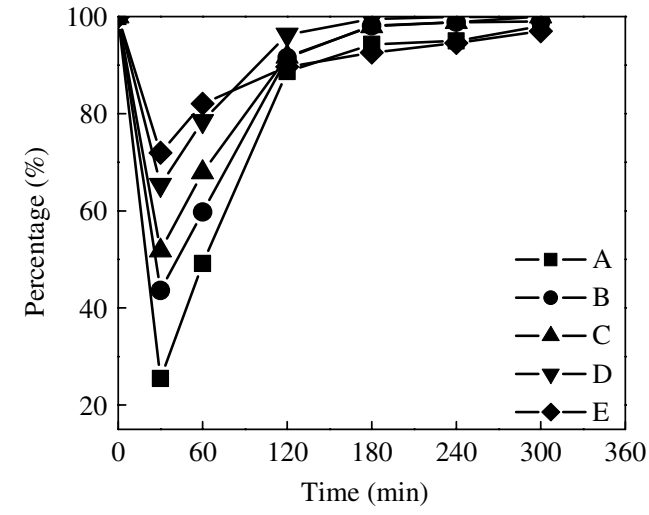

Figure 7. Balance of OCS over different particles at $293 \mathrm{~K}$ during the hydrolysis reaction. (A) $\mathrm{ZnO} / \mathrm{Al}_{2} \mathrm{O}_{3}$ (B) $\mathrm{Fe}_{2} \mathrm{O}_{3} / \mathrm{Al}_{2} \mathrm{O}_{3}$ (C) $\mathrm{Fe}_{2} \mathrm{O}_{3} \mathrm{Al}_{2} \mathrm{O}_{3}$ (D) $\mathrm{CaO} / \mathrm{Al}_{2} \mathrm{O}_{3}$ (E) $\mathrm{Al}_{2} \mathrm{O}_{3}$.

The metal-modified $\mathrm{Al}_{2} \mathrm{O}_{3}$ showed a significant increase in the initial catalytic activity during the reaction time shown in Fig. 6, which was particularly apparent for the $\mathrm{Zn}$ and $\mathrm{Fe}$ modified $\mathrm{Al}_{2} \mathrm{O}_{3}$. At $30 \mathrm{~min}$, the increase of $\mathrm{CO}_{2}$ reached the maximum; however, the enhancement in activity was short-lived, and especially after an hour, their catalytic activities slowed down sharply. From a comparison of the initial and final intrinsic activities, it could be noted that all the modifiers increased both the initial and final activities. This demonstrated that these modifiers were acting as catalyst promoters and were forming a more active catalyst surface in spite of their smaller surface areas (Table 1). In Fig. 7, all of the modified $\mathrm{Al}_{2} \mathrm{O}_{3}$ samples gave a distinct change of OCS after the hydrolysis reaction on the modifiers. It was particularly notable for the hydrolysis reaction of OCS on the $\mathrm{Zn}$-modified $\mathrm{Al}_{2} \mathrm{O}_{3}$, and the OCS percentage even fell to $25.5 \%$ at $30 \mathrm{~min}$, which was less than others. All these proved that the addition of metal to $\mathrm{Al}_{2} \mathrm{O}_{3}$ could provide a significant enhancement in the OCS hydrolysis reaction.

For the hydrolysis reactions on $\mathrm{Al}_{2} \mathrm{O}_{3}$ and modified $\mathrm{Al}_{2} \mathrm{O}_{3}$, with more $\mathrm{CO}_{2}$ formed, the conversion of OCS became less, and it might be explained that the formed $\mathrm{CO}_{2}$ was adsorbed on the particle surface and it competed with OCS for taking the active centers of the particles. ${ }^{[10]}$ Here, we did not find any gaseous phase $\mathrm{H}_{2} \mathrm{~S}$ reported in other references, because in our reaction system, the vapor flow was not controlled, and the formed $\mathrm{H}_{2} \mathrm{~S}$ might react with metal oxides and produce metal sulphide with the existence of enough vapor. To prove our supposition, the diffuse spectra of $\mathrm{Zn}$ modified $\mathrm{Al}_{2} \mathrm{O}_{3}$ before and after the experiments are given in Fig. 8.

As shown in Fig. 8, there was a wide strong peak at $3550 \mathrm{~cm}^{-1}$, which usually belongs to the water adsorbed on the surface, and the middle peaks appearing at 1646,1550 , and $1378 \mathrm{~cm}^{-1}$ were due to $\mathrm{CO}_{2}$ 


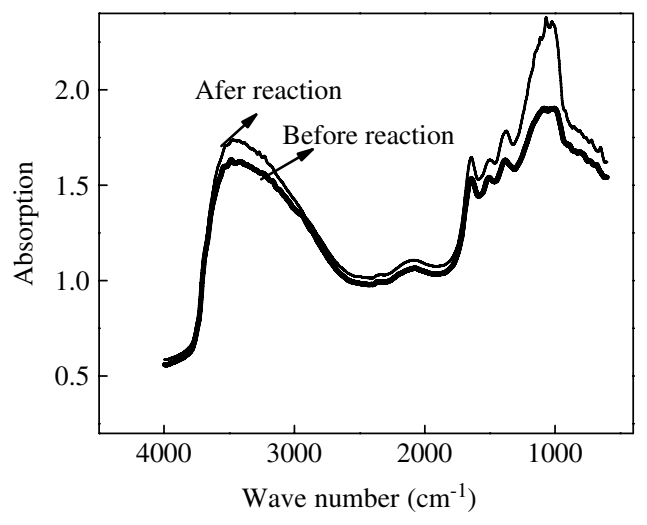

Figure 8. The IR spectra of $\mathrm{Zn} / \mathrm{Al}_{2} \mathrm{O}_{3}$ at $293 \mathrm{~K}$ before and after hydrolysis reaction.

adsorption to form bicarbonate and carboxylate. ${ }^{[11]}$ These peaks increased after hydrolysis reaction since during the hydrolysis reaction, vapor was introduced and more $\mathrm{CO}_{2}$ was formed. We could also see a newly shaped peak appearing at $1072 \mathrm{~cm}^{-1}$ after the reaction. Comparing with the standard IR spectra of $\mathrm{ZnS}$ and $\mathrm{ZnSO}_{4},{ }^{[12]}$ we assigned the absorption at $1072 \mathrm{~cm}^{-1}$ to $\mathrm{ZnS}$. The possible reaction mechanism proposed is as follows:

$$
\begin{aligned}
\mathrm{OCS}+\mathrm{H}_{2} \mathrm{O} & =\mathrm{CO}_{2}+\mathrm{H}_{2} \mathrm{~S} \\
\mathrm{H}_{2} \mathrm{~S}+\mathrm{ZnO} & =\mathrm{ZnS}+\mathrm{H}_{2} \mathrm{O}
\end{aligned}
$$

\section{CONCLUSION}

In our experiments, the OCS consumption on atmospheric particles was very slow and it could include the oxidation and hydrolysis reactions, where the hydrolysis reaction might be more preponderant than the oxidation reaction based on the $\mathrm{Al}_{2} \mathrm{O}_{3}$ model. Metals might play an important role in the hydrolysis reaction by converting OCS into sulfide, and $\mathrm{Zn}$ gave significant catalytic ability. The order of reactivity for the hydrolysis reaction of OCS was: the modified $\mathrm{Al}_{2} \mathrm{O}_{3}$ sample $>$ the unmodified $\mathrm{Al}_{2} \mathrm{O}_{3}$ sample $>$ the atmospheric particle sample.

\section{Acknowledgements}

Financial support from the project of China Natural Science Foundation (20322201) and the Asian Regional Research Programmer on Environmental Technology (ARRPET) sponsored by the Swedish International Development for Research Cooperation Agency (Sida), is gratefully acknowledged.

\section{REFERENCES}

[1] P.J. Crutzen. Geophys. Res. Lett., 1976; 3, 73-76.

[2] U. Baltensperger, M. Ammann, M. Kalberer, H.W. Gaggeler. J. Aerosol Sci., 1996; 27, S651-S652.

[3] S.F. Watts. Atmos. Environ., 2000; 34, 761-779.

[4] L. Wang, F. Zhang, J.M. Chen. Environ. Sci. Technol., 2001; $35,2543-2547$.

[5] H. He, J.F. Liu, Y.J. Mu, Y.B. Yu, M.X. Chen. Environ. Sci. Technol., 2005; 39, 9637-9642.

[6] H.H. Chen, L.D. Kong, J.M. Chen, R.Y. Zhang, L. Wang. Environ. Sci. Technol., 2007; 41, 6484-6490.

[7] R. Fiedorow, R. Leaute, G.A. UaLanaI. J. Catal., 1984; 85, 339-348.

[8] M. Claudio, M. Giuliana. Catal. Today, 1996; 27, 497-532.

[9] R. Shafi, G.J. Hutchings. Catal. Today, 2000; 59, 423-442.

[10] H. Wang, S.S. Tan, H.X. Guo. J. Taiyuan Univ. Technol., 1991; 22, 56-61.

[11] K.B. Kyoko, S. Kazuhiro, K. Hitoshi, O. Kiyomi, A. Hironori. Appl. Catal., A, 1991; 165, 391-409.

[12] Spectral Database for Organic Compounds http://riodb01.ibase. aist.go.jp/sdbs/cgi-bin/direct-frame-top.cgi [15 July 2008]. 